\title{
EDITORIAL
}

\section{China: a life sciences giant}

\author{
Life science research in China continues to expand rapidly. Support from the Chinese \\ government and a thriving research community, including in the field of microbiology, are \\ making China an increasingly important contributor to the life sciences.
}

A recent press release from Nature China showed that the number of articles published by Chinese researchers in five top research journals (Cell, Science, Nature, The Lancet and The New England Journal of Medicine) nearly doubled between 2008 and 2009, providing a clear indication of the growth of life science research in China. Since 2007, China has ranked second only to the United States in terms of the number of scientific publications produced, and the indication is that the trends of increasing quantity and, importantly, quality will continue for the foreseeable future. The most impressive gains have been made in material science and physics, with publications from Chinese authors in the period 2003-2007 accounting for $16 \%$ and $13 \%$ of worldwide publications, respectively. The life sciences have lagged behind compared with these two fields, although microbiology was one of the strongest areas, with $4.4 \%$ of the world's microbiology publication output during this period coming from China.

Two factors in particular make China a 'hotbed' for science. First is the continued increase in funding for science and technology from the Chinese government. Expenditure on science and technology research and development (R\&D) has increased fivefold between 2000 and 2010 and has doubled as a percentage of the gross domestic product (GDP) during this time. The science and technology budget for 2009 increased by $25.6 \%$ compared with the budget for 2008, and the plan for 2006-2020 calls for an investment in R\&D of $2.5 \%$ of the GDP by 2020 . As the economic status of China continues to improve, it is expected that funding for science will continue to increase. This is in stark contrast with the US National Institutes of Health budget, which has been virtually unchanged since 2004 (with the exception of the recent one-off economicstimulus package), and although the science budget in the United Kingdom has grown steadily in recent years, the future, as in many other countries worldwide, is less clear. In relation to GDP, expenditure on R\&D in the United States and Europe has changed little over the past 20 years. China is one of the few countries where the science budget and research community are still growing rapidly.

The second factor contributing to China's scientific growth is the knowledge and experience that is being brought back to China by the 'sea turtles' - Chinese scientists who have trained overseas and then returned home. Their numbers are rapidly increasing: in 2008 alone, 70,000 reseacrhers returned, a 60\% increase on the number returning in 2007, according to the Chinese Education Ministry. Many return after graduate education or postdoctoral training, but more experienced sea turtles also return. One of the most high profile of these is the neuroscientist Yi Rao, who moved from a faculty position at Northwestern University in the USA to become dean of the School of Life Sciences at Peking University in China. Others have returned to start companies, to use their international experience to work for large pharmaceutical companies or to obtain faculty positions.

But substantial hurdles remain, one of the most important of which is language. English is the lingua franca of the scientific world, and so, to interact with their colleagues worldwide, Chinese scientists must become proficient in English. In addition, the Chinese education system has progressed but is still not at the level of other countries, and the best students still often leave for graduate education in the United States or Europe. Although this provides the country with more potential sea turtles, it also decreases the quality of the researchers that are educated in China. However, the quality of the education and research is on the rise, as indicated by the increase in the number of high-impact papers, so more top students may be persuaded to undertake their entire education in China.

A smaller but not insignificant hurdle is that different Chinese names are transliterated to the same western name. A search for an individual on PubMed can easily find well over 1,000 articles, making it difficult for Chinese researchers to 'make a name' for themselves (this problem is not unique for Chinese researchers; a search in PubMed with 'Smith A' returns over 2,600 articles). The Open Researcher and Contributor ID (ORCID) proposal, which gives every researcher a unique identifier, may help to alleviate this problem.

Further improvements in education and the return of many sea turtles should help solidify China's position as one of the world's main growth areas in the life sciences, including microbiology.

FURTHER INFORMATION

ORCID: http://orcid.org

ALL LINKS ARE ACTIVE IN THE ONLINE PDF 